\title{
Research through design: developing a visual language for farm soil mapping
}

\author{
Jacqueline Gothe, Chris Gaul, Andrea Koch
}

research through design, information design,

The contribution of the information designer and design researcher in an data visualisation, collaboration, transdisciplinarity, visual knowledges, soil mapping, geospatial visualisation, cartography interdisciplinary team is examined through the Developing a Visual Language for Farm Soil Mapping Project. The possibilities of digital information to support soil understanding on specific landholdings is at the forefront of the intention of this information design and visualisation project. This collaboration between designers and design researchers, product developers, soil scientists, agronomists and software developers provides a site of research to chart the participation of the designers and design researchers in the Soil Tech Project 2019-2021. The research through design relationally describes the initial participation by the information design team, the contribution of design and design research to the research and development team and the emergence of insights that have relevance for information design, data visualisation, software development, geography, cartography and directly for digital soil mapping.

\section{Introduction}

The role of the information designer in the practices of data visualisation can be misunderstood and many software developers still are unaware of the full potential of collaborating with information designers and design researchers. Research and development teams often call on visual designers to provide the services of visual refinement rather than as partners and collaborators fundamental to the project research and development.

This paper investigates the interdisciplinary nature of collaboration between product developers, soil scientists, agronomists, software developers, designers and design researchers in Australia. The research questions the relation of disciplinary expertise in an emergent practicebased design process, and foregrounds the need for transdisciplinary research approaches in information design in order to transcend disciplinarity. It does this by bringing visibility to insights and research that intersect disciplinary practices of information design, data visualisation, soil science, cartography and software development.

Taking a research through design approach, allows for the iterative and ongoing emergence of questions that have relevance for other disciplines as well as heightening and deepening the application and communication of soil science in a digital context. 
This paper charts the relational process of the inclusion of the designer and design research team in the Soil Tech Project and documents the process of investigation through design to develop a visual language system for colour gradients for soil attributes and the soil texture triangle that are used in digital mapping of farm soil for agronomists and farmers. These visual systems can also be used to communicate attributes of soil through data sets for software tools in digital soil mapping, geography, cartography and geotechnical engineering.

\section{Methodology-research through design}

Research through design refers to inquiry that systematically engages through the intersections of the practice of design, design research and the sites of research. Embracing this pluriversality ensures the recognition of the irreducibility of complexity-a requirement of designerly research (Jonas 2012, p.31; Downton, 2003, p.99; Gothe, 2016) and transdisciplinarity (Nicolescu, 2002a). This research approach is value-based and concerned with ways to negotiate the improvement of real-world situations (Jonas, 2012) recognising the specificity of the material and conceptual results (Downton 2003; Jonas 2012). In this case study, the intersectionality between practices in information design, data visualisation, soil science, agronomy, software development and cartography are brought into visibility.

Kominsky et al (2019) propose opening the black box of visualisation through reflexivity. This paper takes up that challenge through a study of the relations that produce the information design and data visualisations for the Soil Tech Project and reconnecting to findings in cartography (Metternicht \& Stott, 2003; Metternicht \& Goetting, 2007). In this investigation, the practices of information design and visualisation draw on the work of Johanna Drucker's framing of 'visual epistemology' and 'knowledge generating' artefacts in context, use and artefactual experience (Drucker, 2014).

The possibilities of digital information to support soil management and agronomy on specific landholdings is at the forefront of the intention of this information design and visualisation project. In this collaboration between soil scientists, agronomists, product and software developers with designers and design researchers, attention to the design of information and the digital delivery of visualisation and data driven tools for farmers and agronomists is central.

This research is focussed on a study of the use of colour gradients to represent geospatially specific attributes of soil and in particular the soil texture, the highly variable combinations of sand, silt and clay content that provide a basic understanding of soil type in any particular location.

Questions of mediation, representation, translation and knowledge generation are considered as the technology-oriented 
data visualisation context engages with critical information design practices and design enquiry.

\section{Soil Tech Project Overview}

The Soil Tech Project is a three year project funded by the Australian Department of Agriculture, Water and Environment through the LandCare Smart Farming Partnership Fund.

The project is led by Andrea Koch Principal of Agtech Ideation Pty Ltd., whose focus is technology innovation in the agriculture sector. The project partnership includes senior soil scientists from the University of Sydney; software product manager and developers from Agtech Ideation and FarmLab, an agtech software development start-up; and agronomists from AGRIVision Consultants, a Victorian agronomy firm. The project aims to translate six published soil science research papers by University of Sydney soil scientists into a set of digital soil management tools for landholders. The emergent code, algorithms and digital implementation of the science is a new digital soil mapping capability that is referred to as 'Farm Soil Mapping'.

The Farm Soil Mapping tools use statistical methods to combine public geospatial data and farm-scale geospatial and soil test data to make a high-resolution 3D model of farm soil that can be used to create paddock scale digital soil maps. The specificity is imagined at the detail of the paddock, at less than 10m resolution laterally and $5-10 \mathrm{~cm}$ vertically down the soil profile, allowing for greater precision in managing soil in farming systems.

The innovation goal is to enable knowledge translation from 'stranded science' (science that is not useful, usable or used) to the applications and tools for digital platforms available as software to be used by farmers, scientists, agronomists and software providers.

Previously, there have been no widely available tools that allow farm land managers to access meaningful decision making soil data at farm scale-for example, the public National Soil and Landscape Grid of Australia only offers soil data at $90 \mathrm{~m}$ resolution, which has limited use at paddock scale.

The intention of the Soil Tech Project is that the Farm Soil Mapping tools will be commercially available for use by agronomists, farmers, scientists, and software providers in the precision agriculture and soil management field.

\section{Methodology of the Soil Tech Project}

The Soil Tech Project initially brought together the disciplines of soil science, user experience (UX) design, agile software development, and agronomy. Project leader Andrea Koch is a polymath who is 
experienced in managing complex, multi-disciplinary product development teams with an end-user focused approach.

Having identified soil science papers that could usefully be translated into digital tools for land managers, the first step in late $\mathbf{2 0 1 8}$ for the project team was to conduct UX interviews with agronomists, and synthesise the results to guide the product design and software development.

Out of this initial market research came a clear definition of the user personas (the intended end-users of the tools)—agronomists and farmers; and a clear problem statement and hypothesis for the project. The problem faced by agronomists and farmers is that they "need a way to efficiently optimise production in a particular zone of the paddock, while at the same time maintaining or improving soil condition in that zone, because that will keep the farm business going and growing over time" (Koch, 2019). The hypothesis therefore, is that "providing soil data to $10 \mathrm{~m}$ resolution for land managers, will enable optimal management/production across the farm, [and that] we will know this to be true when we see farming/production from the soil up" (Koch, 2019).

A series of agile development sprints, book ended with infield testing of the tools by the agronomists, enabled the development of the first iteration of the 'soil tech tools' by the end of 2019. This comprises a set of algorithms and processors that establish farm scale soil data sets and enable the data to be processed to identify soil properties across and down the soil profile.

A second round of UX interviews with agronomists synthesised at the beginning of 2020 led to a critical realisation that visual communication design expertise was crucial in order to present the resultant data in a way that was easily accessible and readable to the end-users. The UX interviews focussed on how agronomists determine available water capacity in soil. Synthesis of the interviews determined that the science of available water capacity is well understood, but that agronomists find it difficult to communicate with their farmer clients about available water capacity of soil, as 'it can't be seen'. Koch determined that the problem to be solved was a visual communication problem.

Koch approached Dr Jacqueline Gothe, design researcher in the School of Design at the University of Technology Sydney, and together they devised an approach to onboarding visual design into the project. A team of three information designers (Isabella Brown, Chris Gaul and Trenett $\mathrm{Ha}$ ) was convened and briefed on an initial visualisation challenge, and their work was presented back to the original team. Following these presentations, Chris Gaul, lead designer and founder of Parallell Lines was commissioned by Koch to join the project team as a visual information designer. However whilst it was obvious to Koch that the discipline of visual design was needed, it was less obvious to the other existing team members who had little context for bringing visual information design into the project. 
It is not unusual for a design team to be asked to introduce and describe their disciplinary contribution to a research team (Gothe 2016). This is a form of advocacy and education for disciplines (in this case, design) in an interdisciplinary research context. In such a presentation, the design researchers articulate their disciplinary practices in order for interdisciplinary participants to comprehend the potential for engagement with designers and design researchers. This is a nuanced presentation and functions differently to pitching (as performed by professional designers). Rather, it is a recognition of commitment and capacity for negotiation in interdisciplinary research processes.

Gaul arranged for a presentation to the project team of soil scientists, agronomists and software developers to describe the value of information design. This presentation, prepared by Gaul and Gothe, drew attention to the potential of information design in an interdisciplinary research context. The presentation focused on the complexity of representation and concerns for users in two case studies-mass transit maps and wind maps. The team agreed that the translation of the soil science could benefit from the thinking and the skills of design and design research to refine and focus the complexity of the knowledge translation in the context of the digital platform.

\section{Design Research and Practice Project}

Gaul was now contributing directly to the realisation of the project hypothesis, however the project also benefited from a research collaboration with the School of Design at the University of Technology Sydney. Jacqueline Gothe established the design research team with Gaul and Koch to ensure a design research focus and enable the reflexive analysis of the practice through documented conversation, observation and mentoring.

This research focus led to the research and practice project Visual Language for Farm Soil Mapping Project. The central challenge was the design of a visual language that intuitively communicates the complexity of soil at the paddock scale for farmers and agronomists. The aim of this visual language is to provide intuitive and clear visual forms to communicate complex soil information generated by the algorithms and digital tools that allow land managers to 'see' their soil and therefore make informed decisions. This visual language then becomes guidelines for the consistent visual representation of farm soil attributes for software developers, scientists, educators and others. 


\section{Research through design-developing a visual language for farm soil mapping}

Farm Soil Mapping enables the creation of three dimensional farm scale spatial data sets about the various properties that make up the soil in a specific location. The novel approach is in the combination of low resolution 'top down' spatial data (e.g. publicly available satellite imagery including NDVI, elevation, radiometrics), with higher resolution farm scale spatial data (e.g. the geospatial yield data from harvesters, or electromagnetic data that can be collected across paddocks), in combination with locational soil data derived from soil samples that are analysed in a soil testing laboratory to provide an accurate report on the attributes that make up the soil.

Soil attributes that can be geospatially mapped include texture (the proportion of sand, silt and clay), bulk density, $\mathrm{pH}$, salt, nutrients (e.g. nitrogen, phosphorus and potassium) and other trace mineral content. Mineral salt layers can constrain plant growth, so knowing where these are and at what depth, is of critical importance, however until now there has not been a way to map or visualise this information.

Farm Soil Mapping enables the visualisation of the soil properties that make soil inherently unique in a specific location, and which are variable down the soil profile. The most fundamental of these soil properties is the texture. Farmers generally have instinctive geospatial knowledge about the texture of the soil across their paddocks, but do not have a way to see exactly where the texture changes occur.

\section{Colour gradients for single soil attributes (properties and nutrients)}

To improve the readability of farm soil visualisations, colour gradients were designed for the soil attributes that farmers and agronomists most often consider (e.g. pH, moisture, available water capacity, carbon and salinity). These colour gradients have been designed to be intuitive: colours for moisture (water) are blue while maps showing the potential to hold water are a desaturated blue. Maps of carbon are brown and maps of nitrogen are green. Differentiating the maps with unique colours makes them easier to tell apart and enables viewers to decode information more easily. The single attribute colour gradients (Fig 1) are perceptually uniform, ensuring the data are represented accurately. These single attribute colour gradients are optimised for viewers with colour blindness-a factor that is made more relevant by the high rate of colour blindness among Australian farmers. There are already colour conventions for a few attributes (for example $\mathrm{pH}$ and NDVI); where these conventions exist, optimised versions of them were designed. 

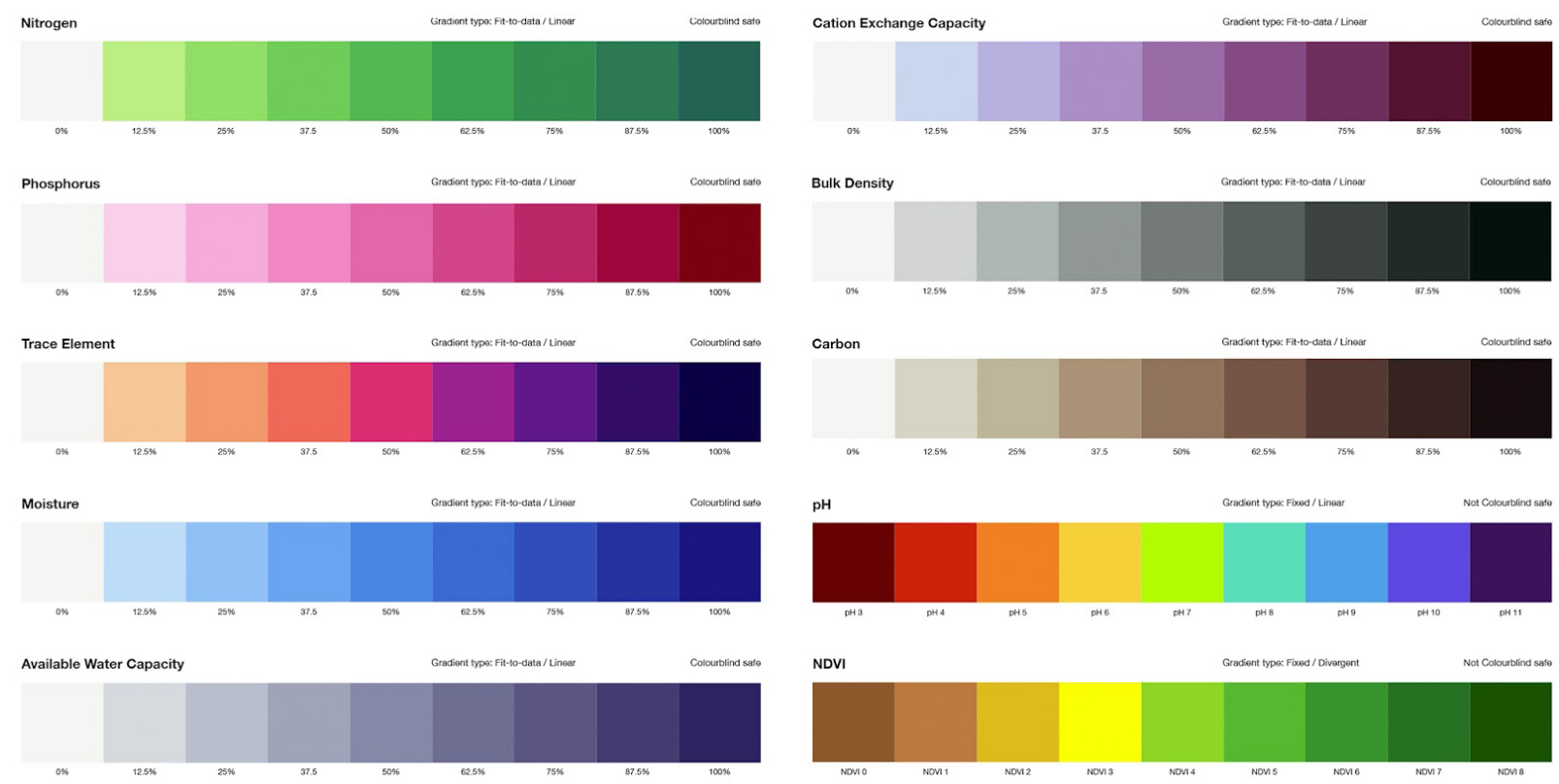

Figure 1 Single value colour gradients that represent commonly considered soil attributes ( $\mathrm{pH}$, moisture, available water capacity, carbon and salinity).

\section{Soil texture triangle}

Soil texture, the highly variable combinations of sand, silt and clay content of soil across the paddock and down the profile, provides a basic understanding of soil type in any particular location, and gives rise to variation in the growth of crops under different conditions (e.g. wetter or drier) and therefore is of fundamental interest in agronomy.

The soil texture triangle is a scientific visualisation that uses a simple visual form to describe the concept of soil texture, as a ternary plot (a visualisation of the ratios of three related variables as positions in an equilateral triangle). This form allows for intuitive comparison of different soils based on their relative positions within the triangle. The soil texture triangle was originally developed in 1911 (Fig 2), and by 1927 (Fig 3) had evolved to the form that is still in use today (Fig 4). Specific soil samples can be represented as points within the triangle. Areas in the triangle can represent different soil texture classes (soils of similar texture that are given names such as 'silty clay' or 'sandy loam'). Different soil texture classification systems are used in different parts of the world, but all cas be mapped to a soil texture triangle.

Farmers, agronomists and scientists around the world rely on the soil texture triangle to make agricultural management decisions.

Over the years, colour has been applied in different ways to the triangle. By and large, these applications have been arbitrary and inconsistent (Metternicht and Stott, 2003).

The challenge in this project was to consider the digital platforms where the colour was in use, and how a colour system for soil texture could be used in conjunction with Farm Soil Mapping to generate 
useful digital maps of soil texture. With careful design, a system of colours could allow the soil texture triangle to be a more rich and effective visualisation for farmers and agronomists.

The result of the design process is a ternary colour gradient where yellow, cyan and magenta represent sand, silt and clay respectively (Fig 5).

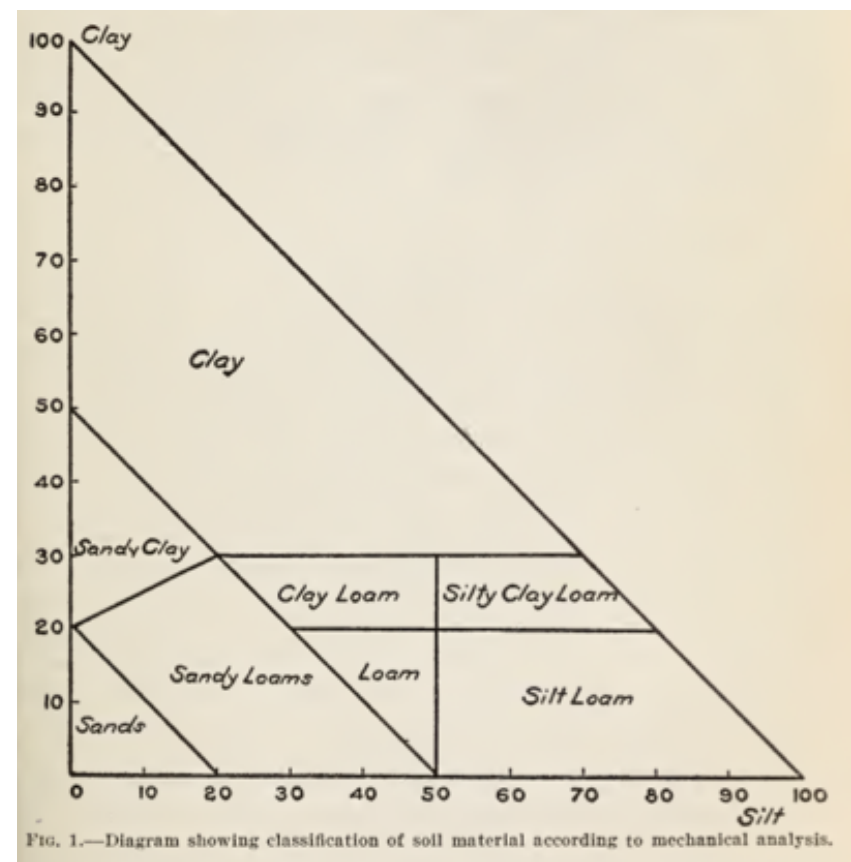

Figure 2 The first published soil texture triangle (Whitney 1911, p. 13).

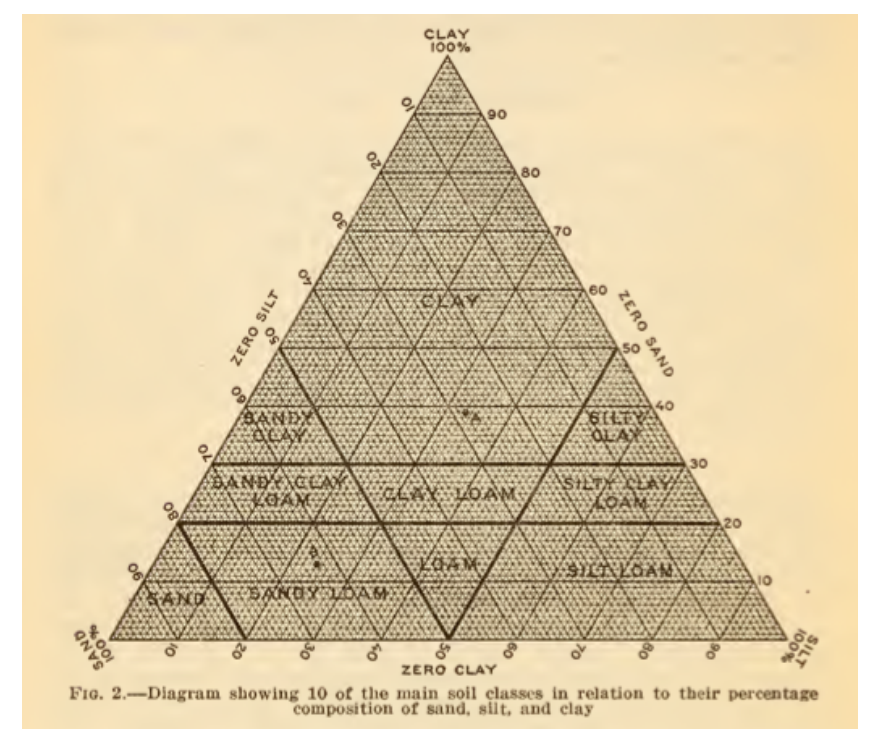

Figure 3 The first equilateral soil texture triangle (Davis \& Bennett 1927, p. 8). Both represent soil texture classes visually within the triangle. 


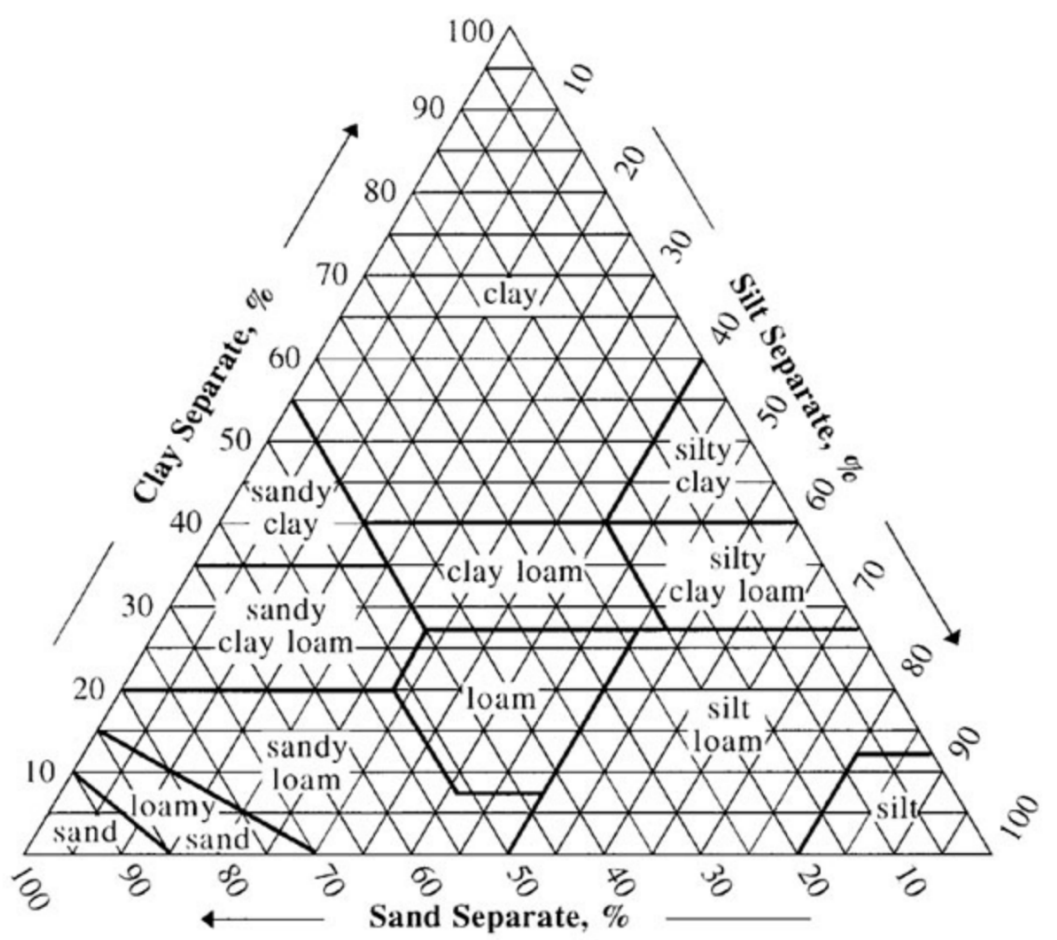

Figure 4 An example of a soil texture triangle that is indicative of the visual representation most commonly used by farmers and agronomists. [Accessed 5 November 2021 from: https://www.nrcs.usda.gov/wps/ portal/nrcs/detail/soils/survey/?cid=nrcs142p2_054167]

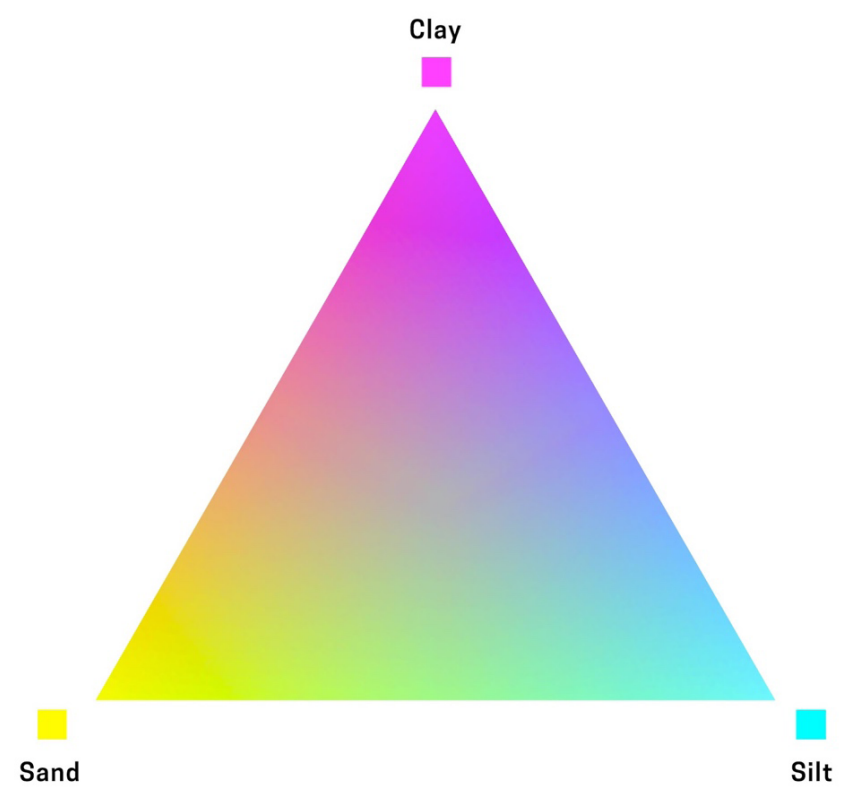

Figure 5 Colour gradients used in Visual Language for Farm Soil Mapping (2019-2021). 


\section{Colour Selection Process}

Designer Chris Gaul's initial intention was to choose the most intuitive colours to represent sand, silt and clay. At first, it seemed best to represent these values with the colours that are naturally associated with them: yellow for sand, an orangy brown for clay and a dark brown for silt. However, feedback from soil scientists in the interdisciplinary project team indicated that this approach may cause the maps of soil texture to be confused for maps of soil colour (soil colour-the actual colour of a soil-is an important scientific and agronomic property of soil).
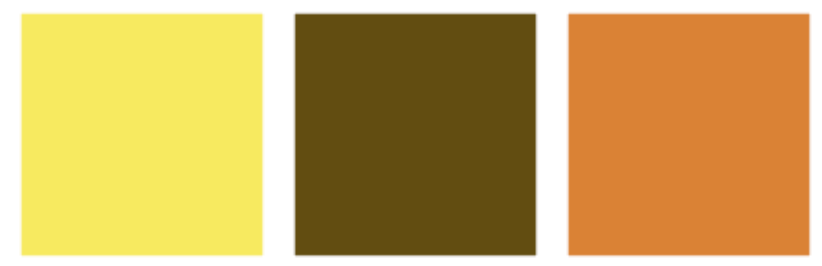

Figure 6 The colours originally proposed to represent (from left to right) sand, silt and clay.

Thus, an abstract colour palette was deemed more appropriate. Given that the majority of viewers of farm soil maps would be viewing the colours on a digital device, it was logical to use the RGB colour gamut-the colour system used to render colours on backlit displays such as computer monitors, tablets and smartphones. Using red, green and blue to represent sand, silt and clay would allow for the most colours in the gradient (as red, green and blue are the primary colours of the RGB gamut). However, the conventional colour system for radiometric maps and data uses red green and blue to represent potassium, thorium and uranium radiation. Agronomists frequently refer to radiometric maps and therefore using the same colour system to represent soil texture would make it difficult to distinguish maps of soil texture from radiometric maps.

For this reason, secondary RGB colours-yellow, cyan and magenta-were chosen to represent sand, silt and clay (Figure 5). This design solution ensures that maps of soil texture are visually distinct from other soil maps, while also allowing for a wide range of colours within the gradient. 


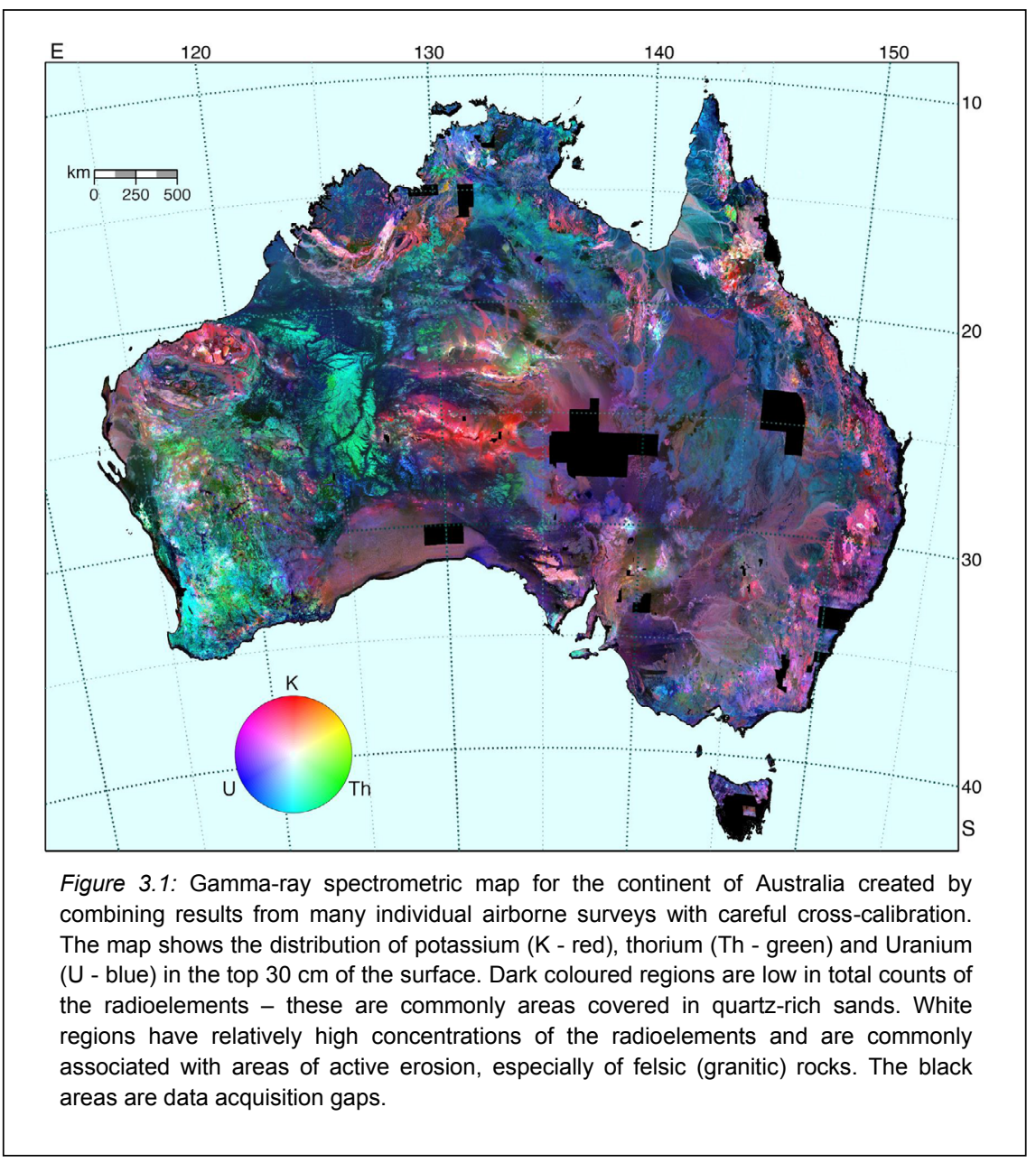

Figure 7 Radiometric map of Australia. Image Credit: Image and description from The Australian Continent: A Geophysical Synthesis, by B.L.N. Kennett, R. Chopping and R. Blewett, published 2018 by ANU Press and Commonwealth of Australia (Geoscience Australia), Canberra, Australia [Accessed 6 November 2021 from http://press-files.anu. edu.au/downloads/press/n4442/pdf/cho3.pdf]
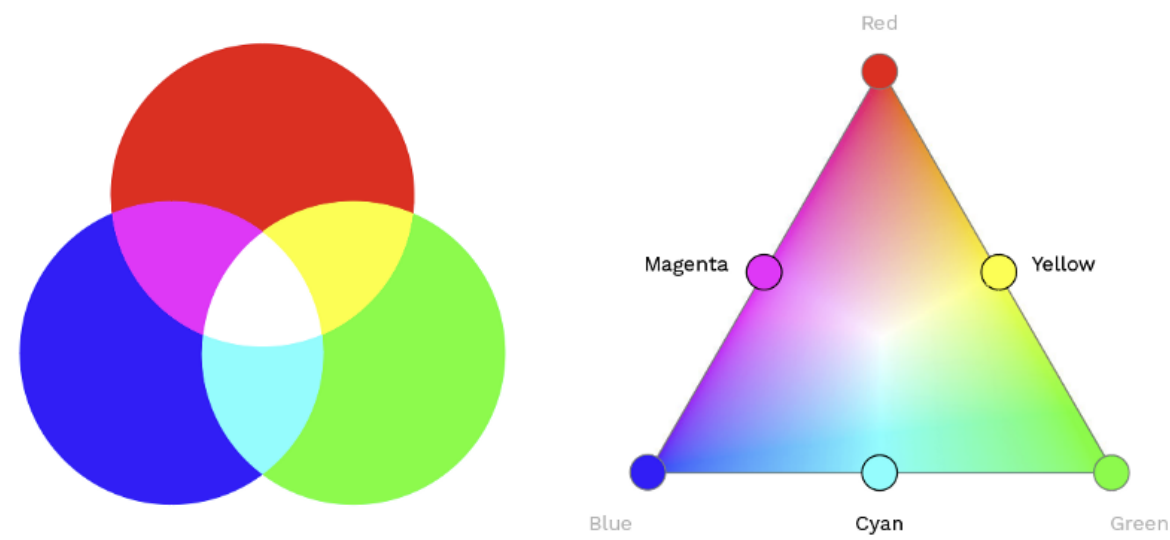

Figure 8 Visualising RGB colour. The secondary colours (magenta, yellow and cyan) are the result of mixing two of the primary colours (red, green and blue). 


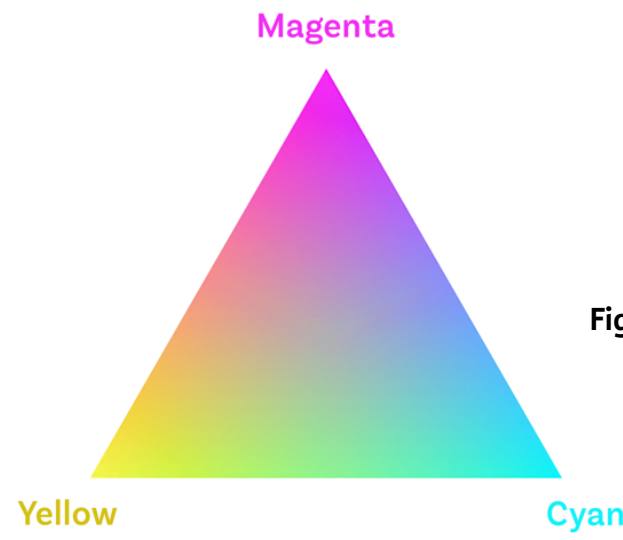

Figure 9 The colour system for the soil texture triangle. The colours yellow, cyan and magenta. are combined in a ternary (three-sided) gradient within the triangle. Yellow, Cyan and magenta are assigned to sand, silt and clay as in Figure 5.
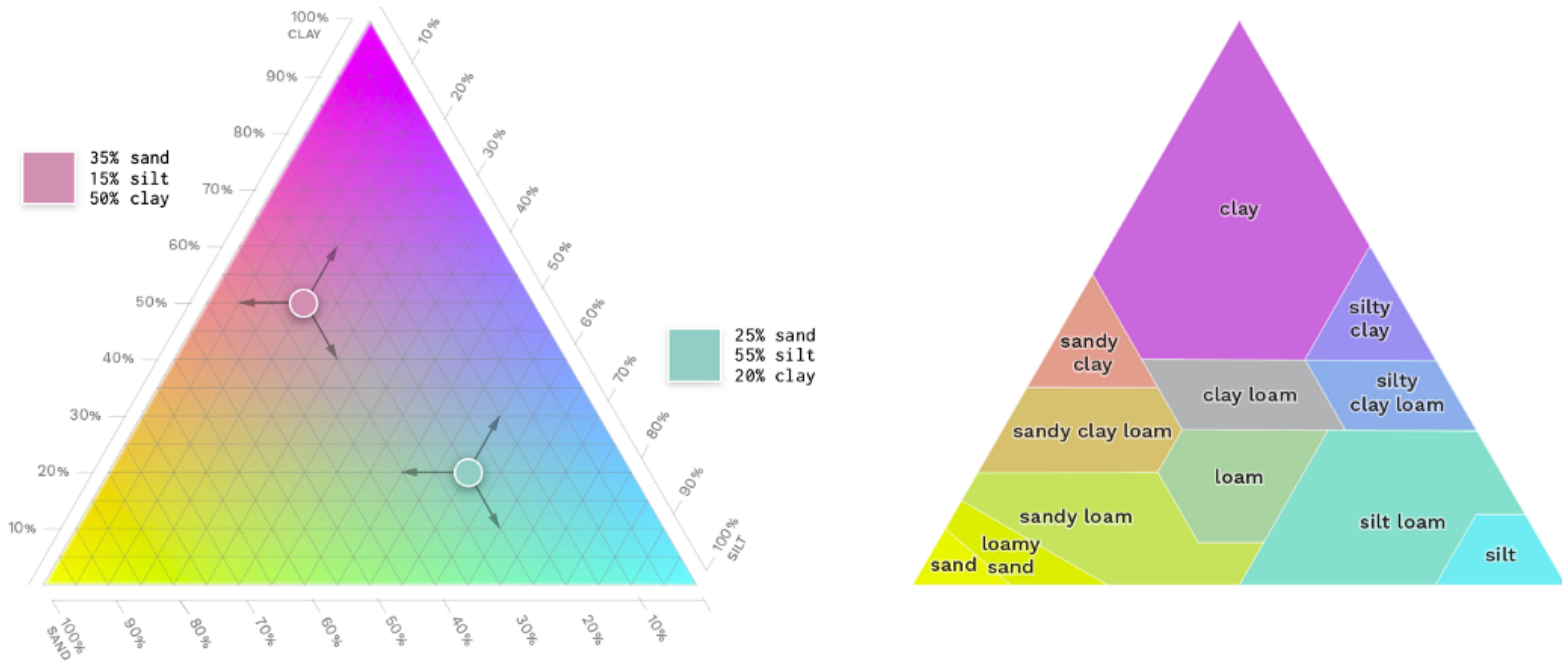

Figure 10 Left: Each point within the triangle has a unique colour (two points are highlighted). Right: Each texture class has a unique colour determined by the colour at its centre point.

In this design:

- Every point within the triangle is represented by a unique colour, which visually describes the relative amounts of sand, silt and clay at that point. These colours allow for an immediate visual understanding of a soil texture value. They also allow viewers to immediately recognise patterns or trends in soil texture data.

- Areas within the triangle are represented by a single unique colour, determined by the colour at the centre-point of the area.

- The colours in the triangle are derived systematically and can be determined mathematically.

- The colours from the triangle can be used in other contexts (maps, histograms, heat maps, or even the labels on jars of collected soil)

- Over time and with consistent application, the colours become familiar and can act as a visual shorthand for soil texture and soil classes. 

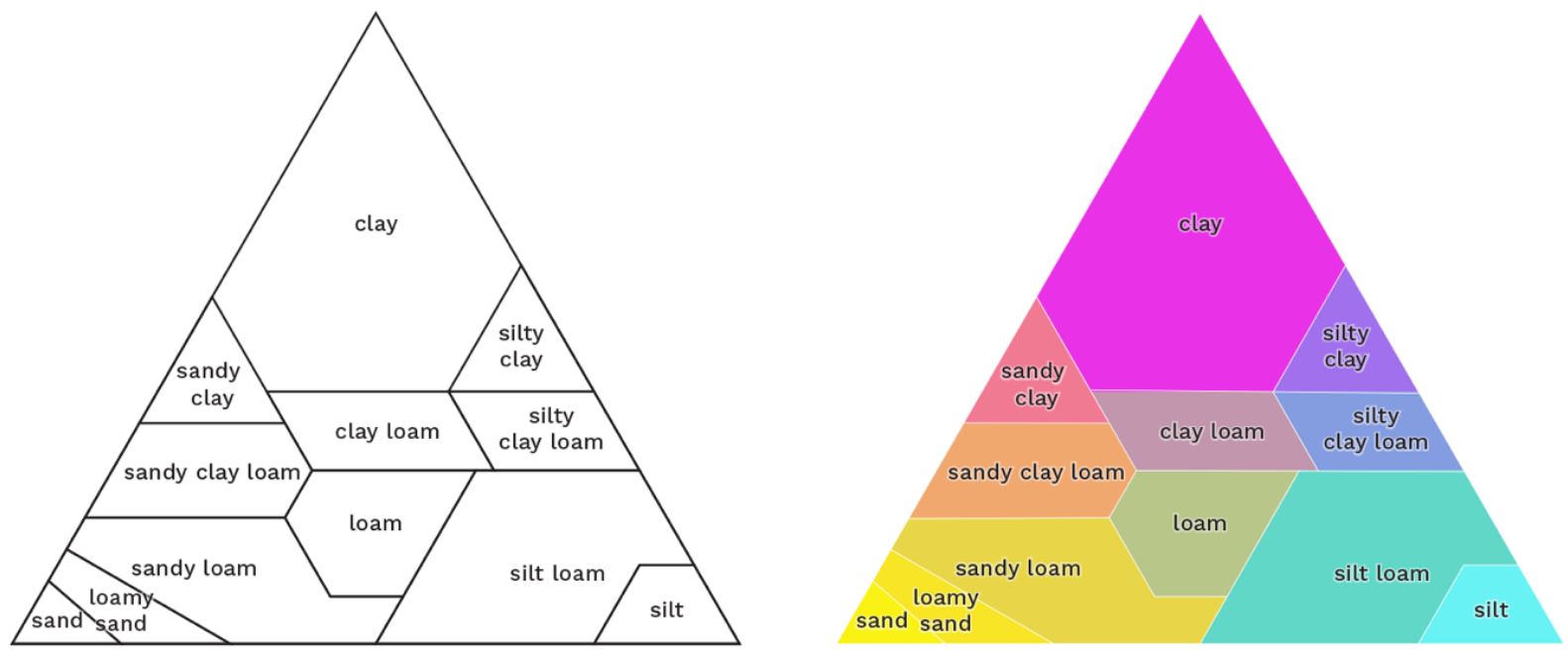

Figure 11 The colours for the USDA soil texture classification system, as derived from the proposed colour system for the triangle.

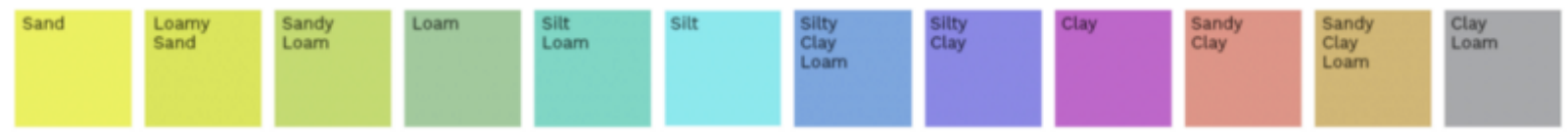

Figure 12 The colours for the USDA soil texture classification system, as derived from Gaul colour triangle.

\section{Accessibility considerations}

People who experience colour blindness would be unable to discern all of the colours in the three sided gradient triangle made up of cyan, magenta and yellow (Figures 9, 10 and 11). This limitation was overcome by using text labels to communicate critical information. This way, the colours are not the only way of comprehending the visualisation, but rather colour is a powerful reinforcement.
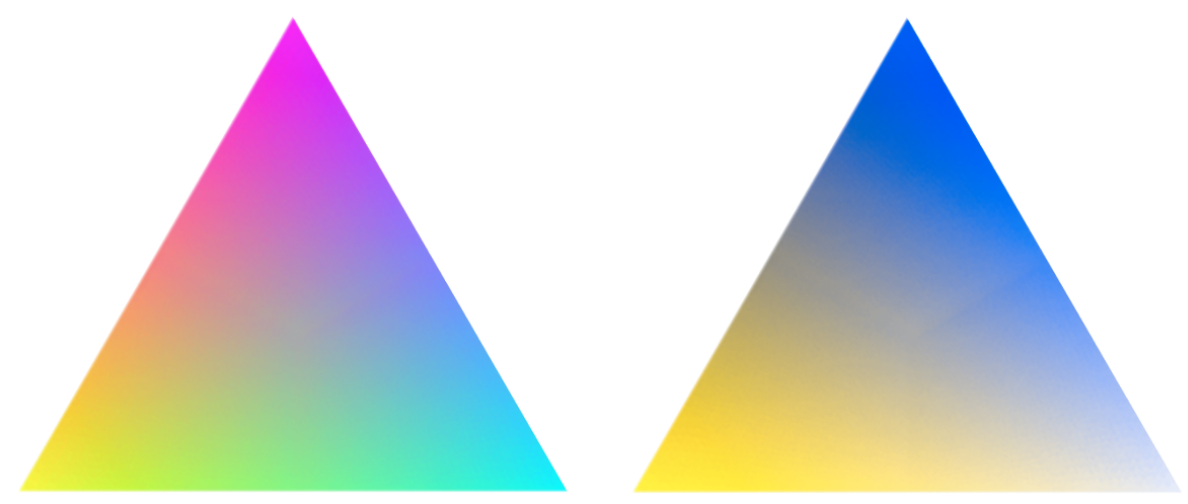

Figure 13 The proposed colour gradient (left) and as these colours appear to a person with protanopia colour blindness (right). 

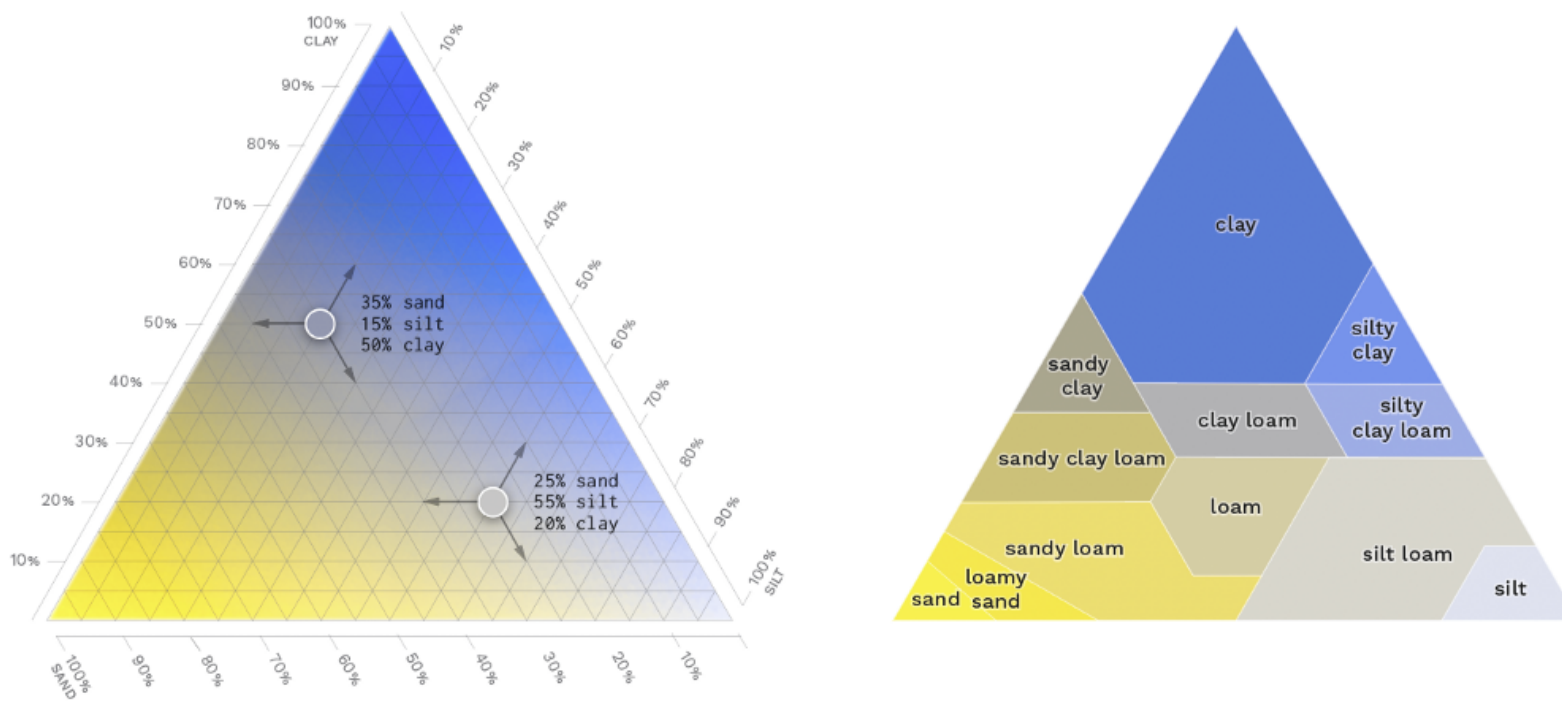

Figure 14 When a secondary graphic element is used-in this case, labels-the colours become a complement rather than the only way of understanding the information. Coloured soil classes (left) and as these colours appear to a person with protanopia colour blindness (right).
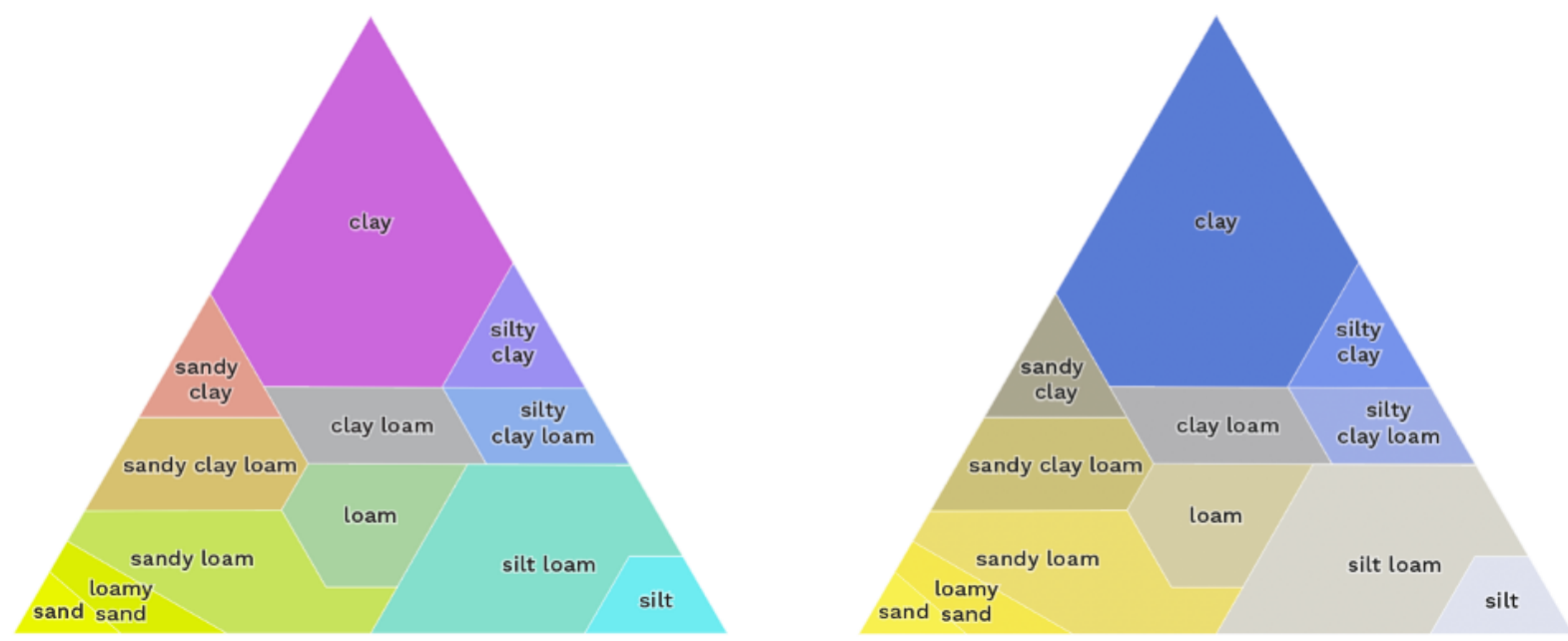

Figure 15 The Gaul colour triangle (left) and refactored for people with protanopia colour blindness (right).

\section{Translation of soil texture triangle visual system to farm soil mapping}

The visual language for the soil texture triangle was designed and applied collaboratively. Gaul worked closely with software developer Kipling Crossing who developed algorithmic rules that enabled the updated triangle to be applied to specific soil data sets, resulting in the encoding of the design into the Farm Soil Mapping toolset.

Figure 16 shows an example of how soil texture data collected through soil sampling and laboratory analysis, and then spatially represented using the Farm Soil Mapping tools, is then visually 

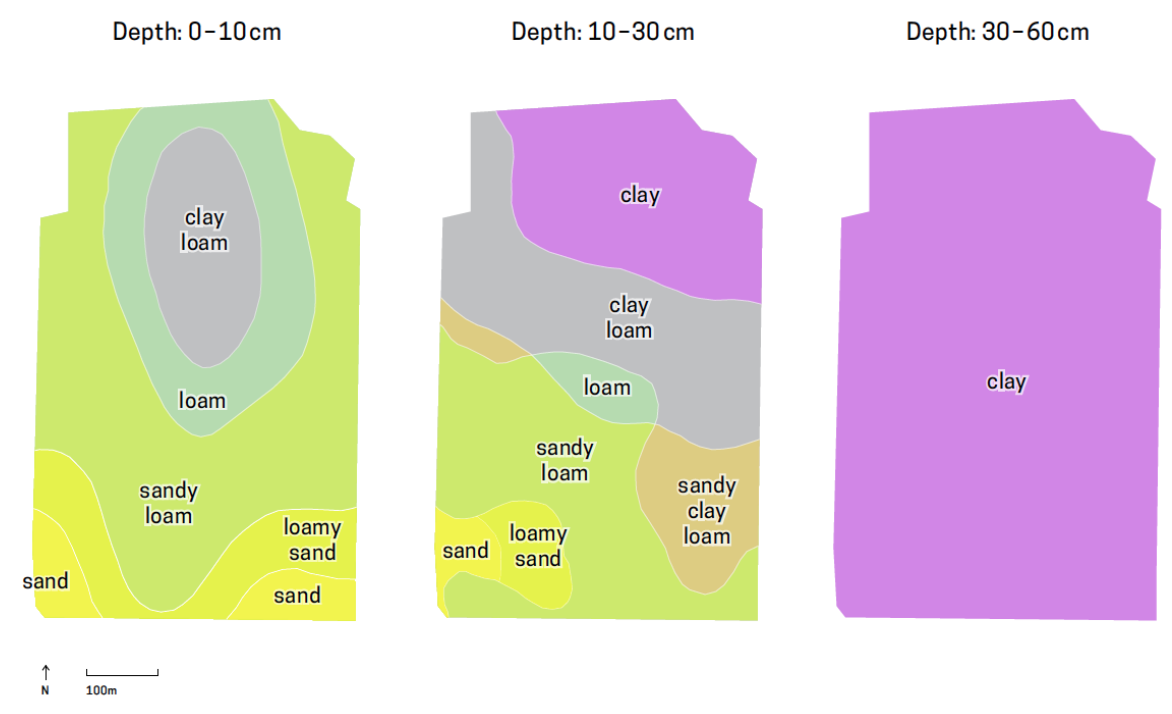

Figure 16 Soil texture maps of a paddock, depicting the soil at the $0-10 \mathrm{~cm}$ layer, $10-30 \mathrm{~cm}$ layer and $30-60 \mathrm{~cm}$ layer down the profile.

represented to the agronomist and farmer, in the form of a series of farm soil maps at paddock scale. The end-user now has very clear and concise information about the types of soil across the paddock, and where those soil types are geospatially located, both across and down the soil profile. This is a major innovation for soil management, and solves the problem that was identified during user experience interviews, that soil agronomists find it difficult to communicate with their farmer clients about their soil, as 'it can't be seen'.

The agronomists on the team recognise the potential for these maps to provide detailed spatial information that can be used to make more precise agronomic decisions in growing crops, including greater input efficiency (use of fertilizers and crop management chemicals) and leading to better soil condition maintenance, thus realising the hypothesis of the Soil Tech Project.

\section{Discussion}

The aim of the Visual Language for Farm Soil Mapping Project is making the visualisation of soil data as usable and useful as possible using fundamental graphic elements and theories of visual perception to improve useability or usefulness. The design research and practice team, in collaboration with the Soil Tech Project team, considered the full range of viewers and users, including people who experience colour blindness and the increasing importance in best practice of data visualisation of perceptually linear colour gradients for clearer analysis from the visual information.

The great innovation in this visual investigation has been to take a visual model that was developed over a hundred years ago-the 
soil texture triangle-and to enhance it to enable a digital application of the model. By being end-user focussed, this design innovation is realised in a format that will ensure its use by its intended audiencefarmers and agronomists.

The papers by Metternicht and Stott (2003) and Metternicht and Goetting (2007) describe a similar system for mapping soil textures. They used CMYK in order to ensure print and digital compatibility whereas in the Visual Language for Farm Soil Mapping Project the RGB system is the colour system of choice in response to the digital use in software applications. According to Metternicht and Stott (2003):

\begin{abstract}
RGB colours do not reproduce faithfully when printed meaning that there will be little relationship between the colours seen on the screen and the colours on the printed map. For this reason, this project adopts the use of the subtractive primary colours, which do not vary so greatly between digital and analogue products, and are based on inks on paper; hence a better representation of colours in printed soil maps is reached. (Metternicht and Stott, 2003:2345)
\end{abstract}

The Visual Language for Farm Soil Mapping Project focuses on digital applications and uses a subset of RGB colours, specifically cyan magenta and yellow. Consequently, the range of RGB colours that can't be reproduced is significantly less. When designing the colours for the triangle, the decision was taken that the greater range of colours that RGB allows for digital displays was worth the minor loss of colour fidelity when printing.

The issue of consistency of colour reproduction across media is complex. Many factors influence the consistency of colour between digital displays and printed documents. In recognising these limitations, it was determined that colour shouldn't be used as the only visual element to communicate data. There should be other elements such as labels or tooltips for redundancy. This way, colour is an indicator that allows for immediate and intuitive understanding, but not the primary way of making precise measurements. Colour alone is not well suited to making precise measurements because people cannot easily distinguish between colours that are similar.

The important differences between the cartographic proposition by Metternicht and Stott (2003) is not only the use of RGB in the digital applications rather than CMYK but more importantly the concern for farmers and agronomists needs at the farm scale. The inclusion of the visual information designer in the Soil Tech team focusses this intention and mediates the fields of data visualisation, software development and soil science in the interdisciplinary team. The contribution of the discipline of visual information design foregrounds the experience of the user in the digital realm. 


\section{Conclusion}

The Soil Tech Project is a unique science translational initiative with a clear focus on the end-users. The original partnership of product and software developers, soil scientists and agronomists, using UX design and agile product development, took the translation so far, however it was the subsequent inclusion of a visual information design professional, and an adjunct design research and practice project with the University of Technology Sydney, that has enabled the emergence of Farm Soil Mapping.

In this investigation, the opportunity for designers and design researchers to engage with soil scientists, agronomists, software developers and farmers created an interdisciplinary context to examine the development of a visual language to visualise farm soil attributes in a digital context for agronomists and farmers.

The successful integration of visual information design into the science translational effort with an end-user focus for the development not only led to success in developing a new digital capability that will enhance soil management by agronomists and farmers, it has been built on significant design innovation around a tried and tested visual tool that has been in use for over 100 years-the soil texture triangle.

In conclusion, this case study demonstrates the clear benefit of taking a research through design approach, and inclusion of visual information design within a multi-disciplinary context in science translational projects, particularly related to landscape and agricultural science. This has ongoing relevance for other disciplines as well as heightening and deepening the application and communication of soil science in a digital context.

\section{References}

Downton, P. (2003). Design Research. Melbourne: RMIT Publishing.

Davis, R. O. E. and Bennett, Hugh (1927) Grouping of soils on the basis of mechanical analysis Retrieved 28 March 2021 from https://archive.org/ details/groupingofsoilso419davi/page/8/mode/1up

Drucker, Johanna. (2014) Graphesis: visual forms of knowledge production Cambridge, Massachusetts: Harvard University Press

Jonas, W. (2012) 'Exploring the Swampy Ground', in S. Grand \& W. Jonas (ed.), Mapping Design Research (pp. 11-41) Basel: Birkhauser.

Kennett, B.LN., Chopping, R.,Blewett, R., The Australian Continent: A Geophysical Synthesis (2018) Canberra, Australia: ANU Press and Commonwealth of Australia (Geoscience Australia). [Accessed 6 November 2021 from http:// press-files.anu.edu.au/downloads/press/n4442/pdf/cho3.pdf]

Koch, A. (2019) The Soil Tech Project - translating soil science into digital soil management apps for land managers. Proceedings of the Conference on 
the Science, Technology, Engineering and Economics of Digital Agriculture, Hosted by the University of Sydney, 3-5 December, 2019

Kosminsky, D., Jagoda, W., Vermeulen,J., Knusen,S.,Willett,W \& Sheelagh Carpendale, S. (2019). Belief at first sight: Data visualization and the rationalization of seeing. Information Design Journal, 25(1), pp 43-55.

Metternicht, G and Stott, J. (2003) Trivariate Spectral Encoding: A prototype system for automated selection of colours for soil maps based on soil textural composition. Proceedings of the 21st International Cartographic Conference (ICC) Durban, South Africa, 10-16 August 2003 Cartographic Renaissance Hosted by The International Cartographic Association (ICA)

Metternicht, G. and Goetting, J. (2007) Towards a standardised approach for the selection of colours in soil maps based on their textural composition and rock fragment abundance: an implementation within Macromedia FreeHand. Conference Paper presented Moscow, Russia July 2007 at the International Cartographic Association

Nicolescu, B. (2007) Transdisciplinarity as Methodological Framework for going beyond the Science-Religion Debate, in B. Nicolescu (ed.), Transdisciplinarity in Science and Religion, Bucharest: Curtea Veche Publishing House. pp. 61-77.

Padarian, J., et al., (2014) Predicting and mapping the soil available water capacity of Australian wheatbelt http://dx.doi.org/10.1016/j.geodrs.2014.09.005

Villagomez, A. (n.d.) A Designers Guide to Colour Blindness [Accessed 30/10/21 https://4ormat-asset.s3.amazonaws.com/vfs/591989/public_ assets/31089524/Colorblind\%20Guide\%20-\%20Web\%2oVersion.pdf]

\section{About the authors}

\section{Dr Jacqueline Gothe}

jacqueline.gothe@uts.edu.au

University of Technology Sydney, Australia

\section{Chris Gaul}

chris@parallellines.design

Parallel Lines

\section{Andrea Koch}

andrea.koch@akagtech.com.au

Agtech Ideation Pty Ltd.

Submission date: 3/5/2021

Approvement date: 24/11/2021 